\title{
Electrochemical top-down synthesis of C-supported Pt nano- particles with controllable shape and size: Mechanistic insights and application
}

\author{
Batyr Garlyyev ${ }^{1, \S}(\varangle)$, Sebastian Watzele ${ }^{1, \S}$, Johannes Fichtner ${ }^{1, \S}$, Jan Michalička ${ }^{2}$, Alexander Schökel $^{3}$ \\ Anatoliy Senyshyn ${ }^{4}$, Andrea Perego ${ }^{5}$, Dingjie Pan ${ }^{6}$, Hany A. El-Sayed ${ }^{7}$, Jan M. Macak ${ }^{2}$, Plamen Atanassov ${ }^{5,6}$, \\ Iryna V. Zenyuk ${ }^{5,6}(\bowtie)$, and Aliaksandr S. Bandarenka ${ }^{1}(\bowtie)$ \\ ${ }^{1}$ Physics of Energy Conversion and Storage, Technical University of Munich, James Franck Straße 1, 85748 Garching, Germany \\ ${ }^{2}$ Central European Institute of Technology, Brno University of Technology, Purkynova 123, 61200 Brno, Czech Republic \\ ${ }^{3}$ Deutsches Elektronen Synchrotron (DESY), Notkestr. 85, 22607 Hamburg, Germany \\ ${ }^{4}$ Heinz Maier-Leibnitz-Zentrum (MLZ), Technische Universität München, Lichtenbergstr. 1, 85748 Garching, Germany \\ ${ }^{5}$ Department of Chemical Engineering, National Fuel Cell Research Center, University of California, Irvine, 92697-2580 California, USA \\ ${ }^{6}$ Department of Material Science and Engineering, University of California, Irvine, 92697-2580 California, USA \\ ${ }^{7}$ Chair of Technical Electrochemistry, Technical University of Munich, Lichtenbergstraße 4, 85748 Garching, Germany \\ ${ }^{\S}$ Batyr Garlyyev, Sebastian Watzele, and Johannes Fichtner contributed equally to this work.
}

(c) The Author(s) 2020

Received: 21 October 2020 / Revised: 24 November 2020 / Accepted: 2 December 2020

\begin{abstract}
In this work, we demonstrate the power of a simple top-down electrochemical erosion approach to obtain Pt nanoparticle with controlled shapes and sizes (in the range from $\sim 2$ to $\sim 10 \mathrm{~nm}$ ). Carbon supported nanoparticles with narrow size distributions have been synthesized by applying an alternating voltage to macroscopic bulk platinum structures, such as disks or wires. Without using any surfactants, the size and shape of the particles can be changed by adjusting simple parameters such as the applied potential, frequency and electrolyte composition. For instance, application of a sinusoidal AC voltage with lower frequencies results in cubic nanoparticles; whereas higher frequencies lead to predominantly spherical nanoparticles. On the other hand, the amplitude of the sinusoidal signal was found to affect the particle size; the lower the amplitude of the applied AC signal, the smaller the resulting particle size. $\mathrm{Pt} / \mathrm{C}$ catalysts prepared by this approach showed $0.76 \mathrm{~A} / \mathrm{mg}$ mass activity towards the oxygen reduction reaction which is $\sim 2$ times higher than the state-of-the-art commercial Pt/C catalyst $(0.42 \mathrm{~A} / \mathrm{mg})$ from Tanaka. In addition to this, we discussed the mechanistic insights about the nanoparticle formation pathways.
\end{abstract}

\section{KEYWORDS}

electrochemical synthesis, platinum, nanoparticles, oxygen reduction reaction

\section{Introduction}

The shape, size and composition of metallic nanoparticles (NPs) often play a decisive role in achieving specific surface functionality for various applications [1-3]. For instance, the properties of metal NPs can be tailored by changing the aforementioned parameters for their applications as heterogeneous, electro- and photo-catalysts as well as in biosensors [4-9]. Currently, most of the state-of-the-art synthetic procedures in nanochemistry are based on colloidal wet-chemical "bottom up" approaches, which often require complex steps. In most cases the shape of the nanoparticle is controlled by surfactants [10-12] or by predefined templates [13]. Such surface capping agents often decrease the activity of metal nanoparticles in heterogeneous catalysis, thus requiring additional steps for removal of the surfactants from the resulting species. Another way of making nanostructures is to directly produce them from bulk materials by so-called "top-down" approach, where mostly expensive lithographic methodologies are utilized.

In 1902, F. Haber observed the formation of metal dusts when applying a potential to metal wires [14]. Later on, the phenomenon was investigated by several groups, mainly for the purpose of testing the stability of the metals at high potentials. More recently, Koper et al. have investigated the surface of single crystalline and polycrystalline metal electrodes and reported the onset potentials for the beginning of surface roughening when cathodic potentials are applied [15]. They also reported that, in addition to the applied potential, the evolution of the metal surface roughness patterns was dependent on the electrolyte composition. However, the exact mechanism of such phenomenon is still not well understood, and the role of metal cations present in the solution remains a mystery. There have been various theoretical studies suggesting the adsorption of metal cations onto the electrode surface and the formation of ternary metal-hydride complexes [16]. Another study [17] proposed that the alkali metal cations from the electrolyte are 
intercalated into the metal surface layer to produce intermetallic compounds. However, as of now there are no experimental evidence to support such mechanisms.

Herein, we demonstrate how to use simple synthesis parameters such as the applied electrode potential, frequency and electrolyte composition to produce carbon supported Pt nanoparticles of desired shape and size without any surfactants or reducing agents. In this top-down method the nanoparticles are eroded from the metal wire by applying an alternating voltage with a specific frequency. Extending the method to a three-electrode configuration enabled a precise control of the metal wire potential. By varying electrolyte concentration, composition and voltage pulses we further support the hypothesis that the mechanism of NP formation by this approach is enabled by the presence of alkali metal cations. Moreover, pair distribution function (PDF) analysis reveals strained nature of particles, which indicates that particles are carved out of the bulk samples.

\section{Results and discussion}

The top-down synthesis of nanoparticles is schematically described in Fig. 1(a): The NPs are produced by exposing Pt wires to an $\mathrm{AC}$ voltage in an aqueous solution. The wires are immersed into an electrolyte containing alkali metal cations, and the nanoparticles are eroded from the metal wires under these conditions. The resulting particles can be supported on a desired support (e.g., high surface area "Vulcan" XC72R carbon black was used in this work), which is dispersed in the solution. The nanoparticles are formed on the wire during a cathodic sweep, while an anodic pulse is needed to release them into the electrolyte. Importantly, previous studies found that the presence of reduction-stable cations (e.g., alkali metal cations) in the electrolyte is one of the crucial constants enabling the synthetic route. For detailed information on the experimental procedures used here, please see the experimental section.

In Fig. 1(b), the rate of mass loss of the Pt host material is depicted as a function of the "overpotential", i.e. symmetric potentials against the equilibrium potentials of hydrogen and oxygen evolution reactions in this case. As expected, the mass loss increases with increasing the applied AC voltage. However, it is important to note that nanoparticle formation can only be observed above $\sim 1.5 \mathrm{~V}$ of the overpotential. Several studies [18-24] have argued that NP synthesis can be achieved by applying solely negative alternating potential. Here, we were not able to reproduce these results, as only when the applied potential was sufficiently high to generate both $\mathrm{H}_{2}$ and $\mathrm{O}_{2}$ the formation of Pt nanoparticles was observed. In either potential range of -10 to $0 \mathrm{~V}$ (generating $\mathrm{H}_{2}$ ), or 0 to $10 \mathrm{~V}$ (generating $\mathrm{O}_{2}$ ) (controlled with three electrode set-up), no Pt NPs were observed. In accordance with the mass loss, it is shown that the particle size increases with increasing the amplitude of the potential, when subjected to a symmetric sinusoidal AC voltage at $200 \mathrm{~Hz}$ (see Fig. 1(c)). From these observations, the first conclusion can be derived: At a constant frequency, the higher the applied potential, the larger are the formed nanoparticles. The particle size increases from $\sim 2.7 \pm 1.0 \mathrm{~nm}$ at $\pm 4 \mathrm{~V}$ to $\sim 4.5 \pm 1.8 \mathrm{~nm}$ at $\pm 25 \mathrm{~V}$.

In addition to the potential amplitude, tuning of the shape and the size of the nanoparticles is possible by changing the frequency of the applied potential. Figures 2(a) and 2(b) compare transmission electron microscopy bright-field (TEM-BF) images of the $\mathrm{Pt} / \mathrm{C}$ material synthesized at different $\mathrm{AC}$ frequencies $(20,200 \mathrm{~Hz})$ and wave shapes (sinusoidal and square wave). At $20 \mathrm{~Hz}$ sinusoidal applied potential, a large fraction of cubic particles were observed. Furthermore, at higher frequencies
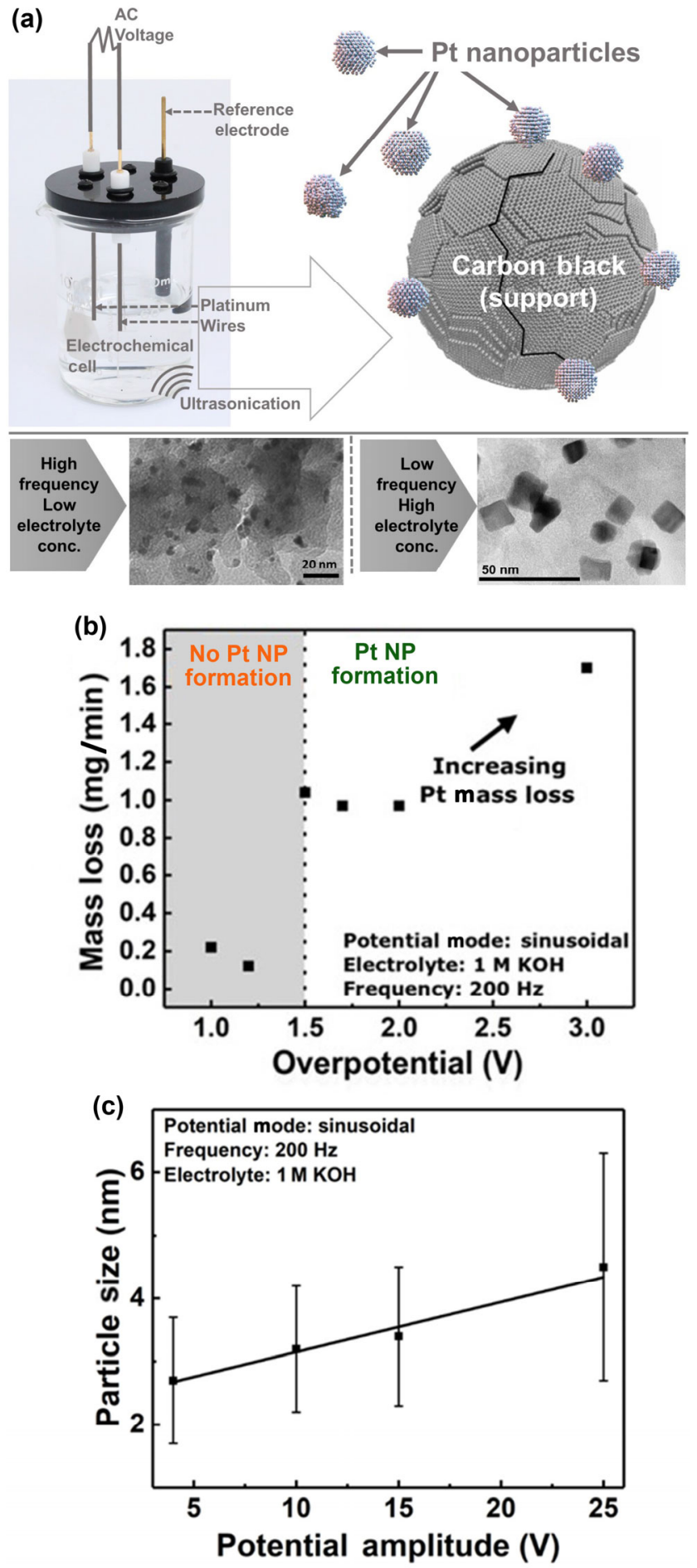

Figure 1 (a) Schematic description of the synthetic procedure used in this work. Illustration highlights which parameters can be tailored to govern the shape of formed particles. (b) Pt mass loss as a function of the "overpotential" (negative potential sweep vs. $0 \mathrm{~V}$; positive potential sweep vs. $1.23 \mathrm{~V})$. (c) Particle size as a function of the AC potential amplitude. Conditions: sinusoidal potential, $1 \mathrm{M} \mathrm{KOH}, 200 \mathrm{~Hz}$.

no cubic particles were produced. This clearly indicates that the shape of the nanoparticles formed depends on the frequency when sinusoidal peak is applied. On the other hand, as highlighted by the magnified images, when square-wave signal is applied, spherical shaped nanoparticles are formed, independent of the frequency of the applied square wave potential. In turn, this indicates that the shape of the nanoparticles can be controlled by changing the frequency of the applied sinusoidal potential. 
(a)

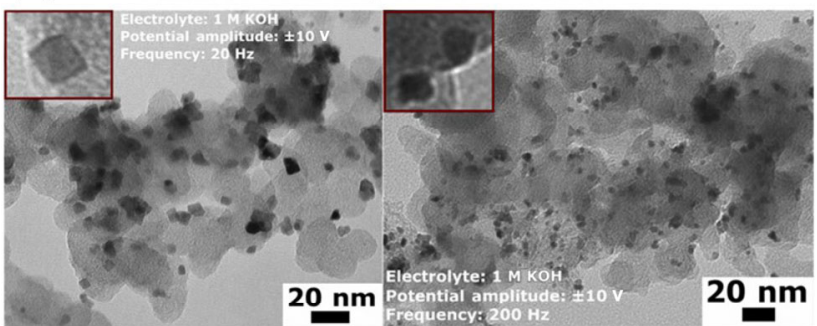

(b)

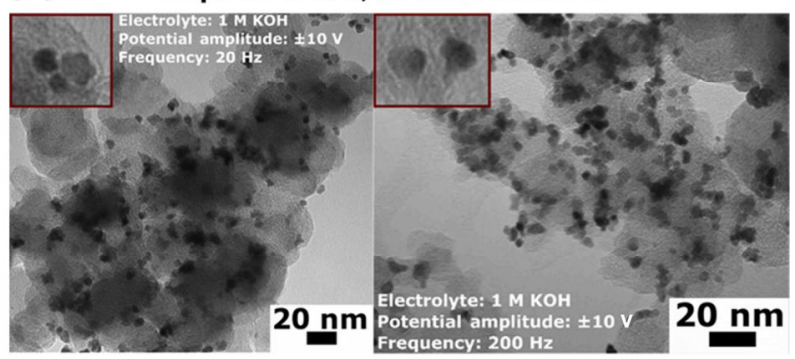

(c)

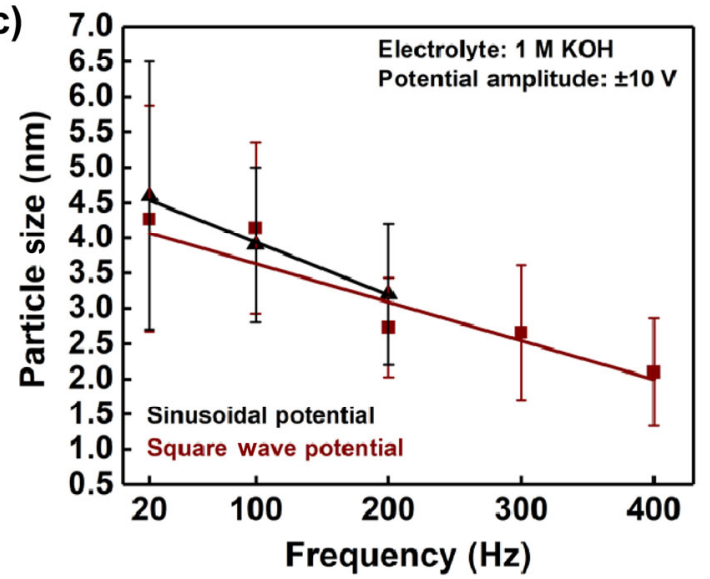

Figure 2 The influence of the wave shape and frequency on the $\mathrm{Pt}$ nanoparticle sizes and shapes. TEM-BF images of the $\mathrm{Pt} / \mathrm{C}$ materials synthesized at $20 \mathrm{~Hz}$ and $200 \mathrm{~Hz}$ using (a) sinusoidal and (b) square wave potential signals. (c) Particle size as a function of the frequency $(20-400 \mathrm{~Hz})$. Synthesis conditions are given in the figures.

Another interesting observation is that the size of the formed nanoparticles does not change with changing between the sinusoidal and square-wave potentials. The results shown in Fig. 2(c) indicate that applying square-wave potentials leads to smaller or comparable mean particle size (considering the standard deviation). Hence, we conclude that within the short formation time at equal frequency, the wave shape has no pronounced effects on the particle size. The increase of the frequency results in a decrease of the particle size for both wave shapes. This is in accordance with a hypothesis that higher frequencies lead to faster nanoparticle formation rates (faster nanoparticle detachment from the bulk wire), this results in formation of smaller nanoparticles. In other words, since the $\mathrm{Pt}$ species were formed in every potential shift cycle, increasing the frequency would reduce the time for the growth of NPs before detachment.

As shown in Fig. 3, the electrolyte composition is another parameter, which can be used to control the particle sizes. Under the given conditions, it was possible to produce particles starting from a concentration of $\sim 0.2 \mathrm{M} \mathrm{KOH}$. At this concentration, generated nanoparticles were $1.9 \pm 0.7 \mathrm{~nm}$ (see Fig. 3(a)). In contrast, the size of the species produced in $5 \mathrm{M} \mathrm{KOH}$ was $11.1 \pm 5 \mathrm{~nm}$ (see Fig. 3(b)). Figure 3(c) highlights the increase (a)

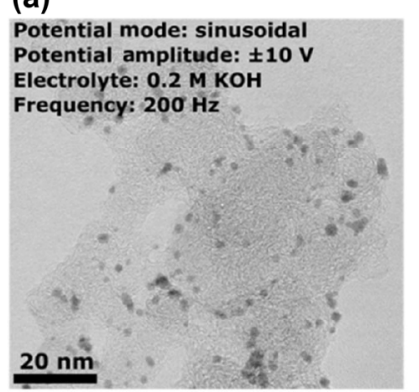

(b)

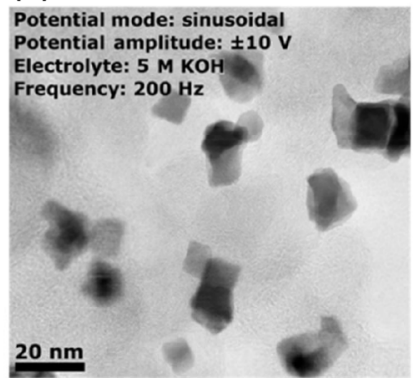

(c)
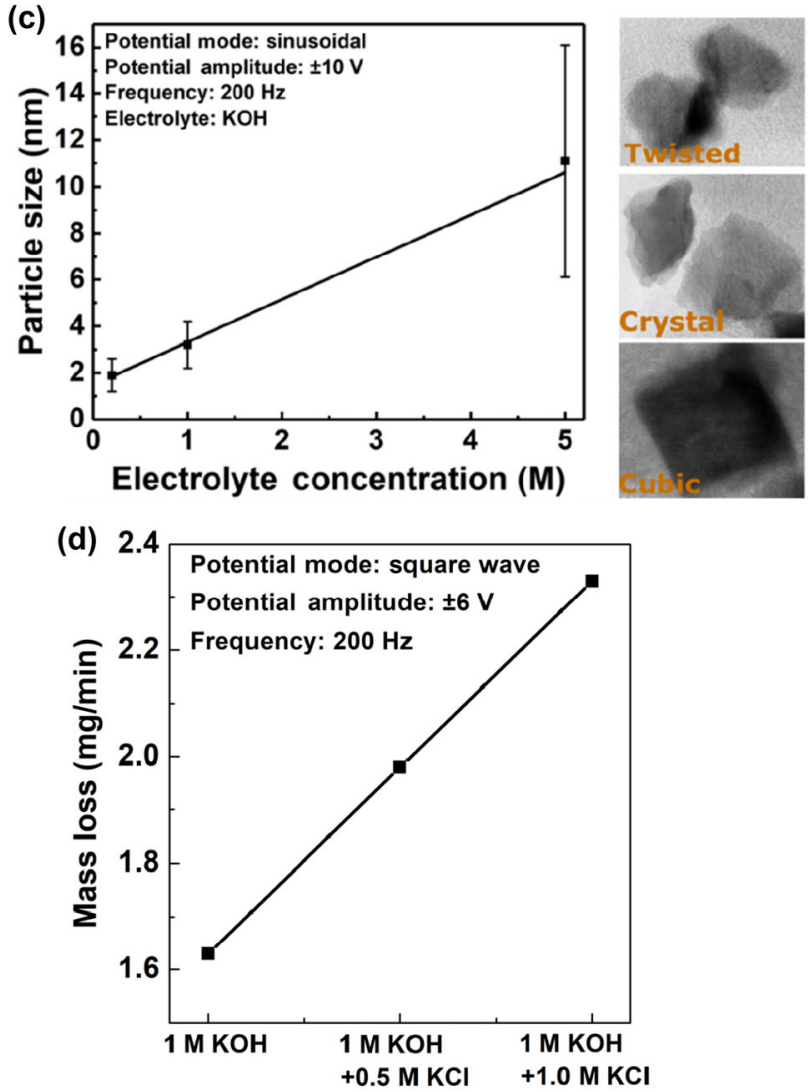

(e)

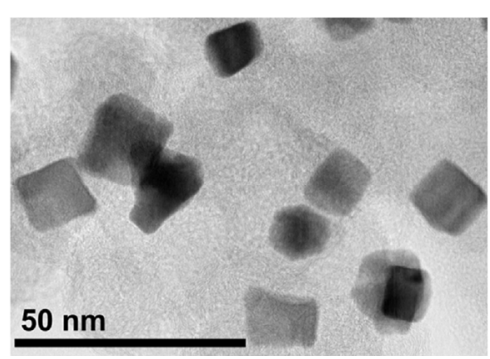

Figure 3 Influence of the electrolyte concentration on the Pt nanoparticle size and shape. (a) and (b) STEM-BF images of Pt/C synthesized in 0.2 and $5 \mathrm{M} \mathrm{KOH}$. (c) Particle size as a function of the electrolyte concentration and magnified STEM-BF images of Pt/C synthesized in $5 \mathrm{M} \mathrm{KOH}$. Conditions: sinusoidal potential, $\pm 10 \mathrm{~V}, 200 \mathrm{~Hz}$. (d) Pt mass loss as a function of the concentration of the $\mathrm{K}^{+}$cations present in the solution. (e) STEM-BF image of cubic Pt nanoparticles. Cubic structure was achieved by altering the electrolyte composition and the frequency of the applied potential $( \pm 10 \mathrm{~V}$ sinusoidal potential at $20 \mathrm{~Hz}, 5 \mathrm{M} \mathrm{KOH})$.

in the size of NPs as a function of the electrolyte concentration, where the particle size distribution also increases for the larger sizes. This is further supported by the increased mass loss at the bulk Pt electrode with increasing the $\mathrm{K}^{+}$cation concentration, as shown in the Fig. 3(d).

A closer look at the corresponding particle shapes via scanning 
transmission electron microscopy with bright-field detector (STEM-BF) in Figs. 3(a) and 3(b) reveals strong morphological differences at different concentrations. At the lowest concentration, small spherical particles can be found, which are homogeneously distributed on the support material. In contrast, in $5 \mathrm{M} \mathrm{KOH}$, a high fraction of cubic particles can be observed. This is in accordance with literature reports, where the appearance of cubic etch holes on the surface of Pt wires has been previously described $[25,26]$. However, here we confirm that this also corresponds to the actual structure of the resulting nanoparticles. Apart from the cubic NPs, one also observes the formation of different particle shapes. As illustrated in Fig. 3(c), some large particles with crystal-like shapes were found, being characterized by very rough, non-uniform edges. Accordingly, the question arises why these different shapes appear. It seems plausible that the shape of the grains and grain boundaries of the host material is an important factor. Furthermore, the particle formation rates could be equally important.

As the electrolyte concentration influences the number of ions at the electrified solid/liquid interface, the local conductivity increases. In turn, this might result in faster particle formation and a less precisely defined shape, while a longer conversion time results in a uniform particle shape.

Lastly, the effect of the nature of the alkali metal cations was investigated. Recent data indicate that the type of electrolyte species has a pronounced impact on the particle shape, leading to a change of the generated surface facets with change of the cation size [16]. As observed by STEM with high-angular annular dark-field detector (STEM-HAADF) and simultaneously by STEM-BF in Fig. 4(a), all particles synthesized in the electrolytes with different cations $\left(\mathrm{Cs}^{+}, \mathrm{Na}^{+}, \mathrm{Li}^{+}\right)$exhibit a strong degree of surface defects. As reported previously, such concave defects can be used to tailor the oxygen reduction reaction (ORR) activity of Pt nanoparticles, verifying the various application possibilities $[4,27,28]$. It has to be noted, that the depicted particles are not representative for the mean particle size, for accurate shape comparison larger particles with similar sizes were pre-selected. Regarding the particle size, no clear trend can be observed, with average mean sizes ranging from 3 to $4.5 \mathrm{~nm}$. We observe slightly larger mean Pt particle size in the case of $\mathrm{NaOH}$. The results shown in Fig. 4(b) indicate that the presence of different alkali metal cations does not influence the size of the produced species.

In an earlier study [15], Yanson et al. did not observe $\mathrm{NP}$-formation in acidic media. In the present work, $1 \mathrm{M} \mathrm{HCl}$ was also used and $\pm 6 \mathrm{~V}$ square wave potential was applied. No Pt NPs were observed under these conditions. We have also used $1 \mathrm{M} \mathrm{KCl}$ solutions of different $\mathrm{pHs}$, where the latter was adjusted by $\mathrm{HCl}$. As it is seen in Fig. 4(c), the higher $\mathrm{pH}$ resulted in higher mass loss from the bulk Pt wire; and at the same time larger amount of gas bubbles were observed. This indicates that the concentration of hydroxide ions also plays a role in the formation rate of the nanoparticles. Below $\mathrm{pH}$ of 2.5, the mass loss of Pt did not change further for the lower pHs.

In order to obtain more information about the crystal structure of the produced nanoparticles, X-ray diffraction measurements were conducted. The obtained diffraction data are plotted in Fig. S1 in the Electronic Supplementary Material (ESM) as received. It can be seen that the diffraction signal is dominated by air scattering. Subtraction of empty capillary/air scattering data from the diffraction patterns leads to a quasi-flat background. Weak contributions from "Vulcan" carbon can be noticed in the diffraction data for $\mathrm{Pt} / \mathrm{C}_{10 \mathrm{v}}, \mathrm{Pt} / \mathrm{C}_{4 \mathrm{~V}}$ (samples related to Fig. 1(c)) and the commercial $\mathrm{Pt} / \mathrm{C}$ samples (TKK, (a) $\mathrm{CsOH}$

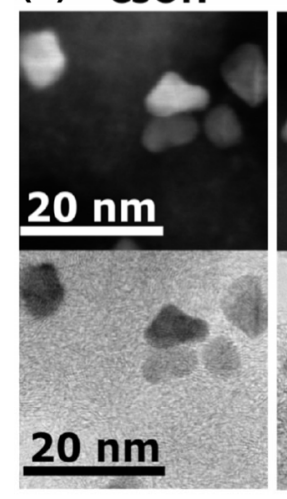

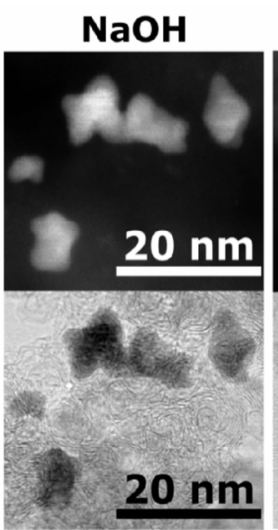

LiOH

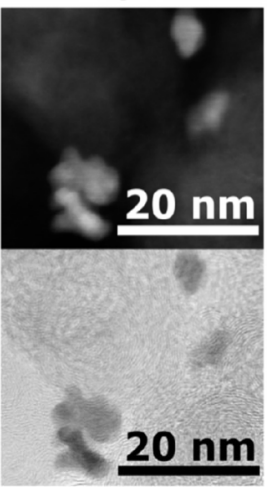

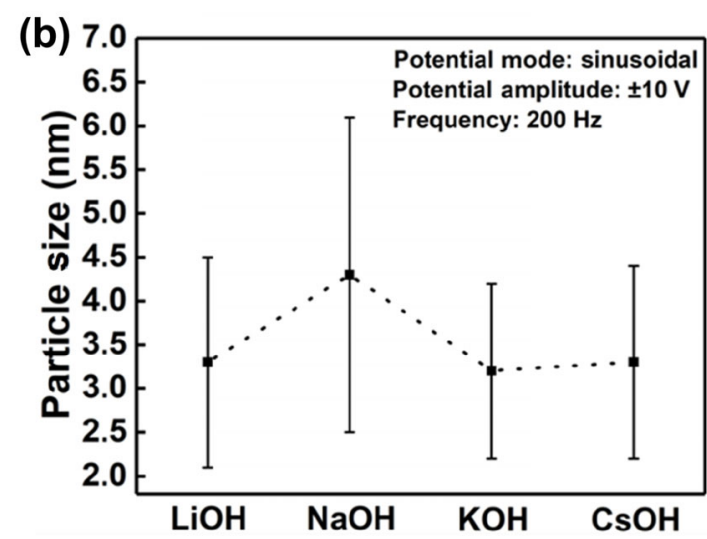

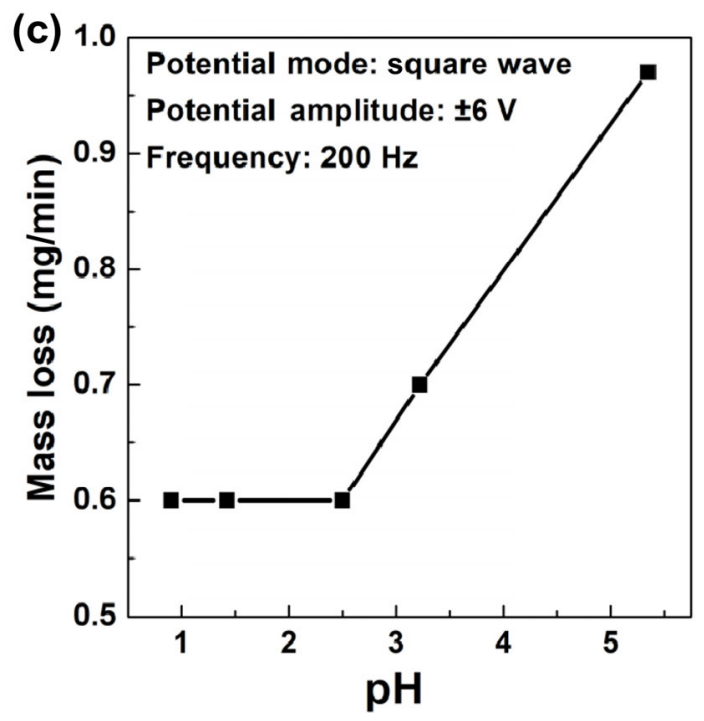

Figure 4 Influence of the electrolyte composition on the Pt nanoparticle size and shape. (a) STEM-HAADF and corresponding STEM-BF images of the $\mathrm{Pt} / \mathrm{C}$ material synthesized in $1 \mathrm{M} \mathrm{CsOH}, \mathrm{NaOH}$ and $\mathrm{LiOH}$. (b) Particle sizes for the solutions containing different alkali metal cations. Conditions: sinusoidal potential, $\pm 10 \mathrm{~V}, 200 \mathrm{~Hz}$. (c) Pt mass loss as a function of the solution $\mathrm{pH}$. The $\mathrm{pH}$ of $\mathrm{KCl}$ solution was adjusted by adding $\mathrm{HCl}$.

Japan) (Fig. S1(b) in the ESM), which can be eliminated by subtraction of the "Vulcan" carbon instead of the empty capillary measurements (Fig. S1(c) in the ESM). In addition, the powder XRD diffractograms of $\mathrm{Pt} / \mathrm{C}$ prepared in $\mathrm{LiOH}$ and in $\mathrm{KOH}$ solutions are shown in Fig. S3 in the ESM, where one can see typical Pt peaks.

Rietveld refinements of the latter datasets yield very similar results (Figs. S1(d)-S1(f) in the ESM). The observed lattice parameters are listed in Table 1 showing a weak spread of $\mathrm{Pt}$ lattice parameters between the three samples. At $4 a$ platinum 
Table 1 Lattice parameters (in $\mathrm{nm}$ ) of Pt extracted through Rietveld and pair distribution function analysis

\begin{tabular}{ccc}
\hline Sample type & Rietveld refinement & PDF analysis \\
\hline $\mathrm{Pt} / \mathrm{C}_{10 \mathrm{~V}}$ & $0.401379 \pm 0.000015$ & $0.401089 \pm 0.00011$ \\
$\mathrm{Pt} / \mathrm{C}_{4 \mathrm{~V}}$ & $0.400821 \pm 0.000033$ & $0.400737 \pm 0.000068$ \\
Commercial Pt/C & $0.399209 \pm 0.000093$ & $0.401194 \pm 0.0005$ \\
\hline
\end{tabular}

site, the following isotropic displacement parameters $0.0056(1)$, $0.0061(2), 0.0092(2) \mathrm{nm}^{2}$, were obtained for the $\mathrm{Pt} / \mathrm{C}_{10 \mathrm{v}}, \mathrm{Pt} / \mathrm{C}_{4 \mathrm{~V}}$ and commercial $\mathrm{Pt} / \mathrm{C}$ samples, respectively. This observation might be the indication of more ordered character of $\mathrm{Pt} / \mathrm{C}_{10 \mathrm{~V}}$ and $\mathrm{Pt} / \mathrm{C}_{4 \mathrm{v}}$ samples over the commercial $\mathrm{Pt} / \mathrm{C}$. The systematic diffraction peak broadening was observed over the whole $2 \theta$ range studied, which was attributed to the particle size effect (assuming spherical shape of particles) and the following average sizes were obtained: $~ 3.1, \sim 2.4$ and $\sim 1.3 \mathrm{~nm}$.

The Rietveld refinement usually provides slightly underestimated coherent scattering lengths, when compared to PDF. The obtained PDF curves are presented in Fig. 5, and graphical results of PDF modelling are plotted in Figs. S2(b) and S2(c) in the ESM for the three samples studied. The PDF of the Pt/C $\mathrm{C}_{10 \mathrm{~V}}$ sample can be well described by the Pt-structure, whereas several spurious peaks with the maxima at ca. $0.13,0.208$ and $0.357 \mathrm{~nm}$ were noticed on the obtained PDF curves for the $\mathrm{Pt} / \mathrm{C}_{4 \mathrm{~V}}$ and commercial $\mathrm{Pt} / \mathrm{C}$ samples. A characteristic signal at $0.13 \mathrm{~nm}$ was attributed to residues of $\mathrm{C}-\mathrm{C}$ bonds from "Vulcan" carbon (probably not ideally subtracted from the data), whereas maxima at 0.208 and $0.357 \mathrm{~nm}$ can be attributed to oxidized platinum, i.e. $d_{\mathrm{Pt}-\mathrm{O}}$ and $\sqrt{3} d_{\mathrm{Pt}-\mathrm{O}}$ [29]. Due to relatively weak contribution from the non-platinum phases, no multiphase modelling was attempted, i.e. further analysis of PDF data yielded 4.36(14), 3.13(4) and 2.06(14) nm average spherical particle sizes for the $\mathrm{Pt} / \mathrm{C}_{10 \mathrm{v}}, \mathrm{Pt} / \mathrm{C}_{4 \mathrm{~V}}$ and commercial $\mathrm{Pt} / \mathrm{C}$ samples, respectively. Similar lattice parameters (Table 1) were noticed for all three samples. Isotropic displacement parameters obtained by PDF confirmed the trend yielded by the Rietveld refinement with $0.0108(4), 0.0113(2)$, and $0.015(2) \mathrm{nm}^{2}$, where commercial sample displays essentially higher values potentially caused by the Pt site disorder.

In the following, we highlight the observations, which could help in deciphering the mechanism of the nanoparticle formation:

- Applied AC voltage should be higher than ca. $\pm 1.5 \mathrm{~V}$, holding at high negative or positive potentials doesn't result in observable nanoparticle generation.

- Alkali metal cations need to be present in the electrolyte. No nanoparticle formation is observed in $\mathrm{HCl}$ solutions without these cations.

- Simultaneous gas evolution during particle formation is needed. In presence of $\mathrm{HCl}$ we observed $\mathrm{Cl}_{2}$ gas, therefore the gas composition seems not to be as relevant.

- In acidic electrolytes, $\mathrm{H}^{+}$and $\mathrm{K}^{+}$seem to compete, and higher applied potentials are needed to locally deplete $\mathrm{H}^{+}$in hydrogen evolution reaction (HER).

- Starting with alloyed bulk precursor structure results in the formation of alloyed nanoparticles, for instance $\mathrm{Pt}_{5} \mathrm{Pr}$ bulk material generates $\mathrm{Pt}_{x} \mathrm{Pr}$ NPs (for more details please see Ref. [5]).

- The type of alkali metal cations doesn't significantly influence the particle size; however, the alkali metal cation concentration affects the NP shape and size.

- Diffraction measurements indicate that the nanoparticles generated by top down method have more strained structure in comparison to commercial particles produced by traditional bottom up approaches, which is important e.g. in electrocatalysis.

All of these observations above strongly suggest that the NPs are carved out of the bulk metal and are not formed through the mechanism where metal ions are dissolved and subsequently reduced to form nanoparticles. Especially, strained structures and feasibility of alloyed nanoparticle generation strongly indicate that nanostructures are being ripped from the bulk material.

Figure 6 shows the oxygen reduction activity results of $\mathrm{Pt}$ nanoparticles produced by electrochemical method in $1 \mathrm{M}$ $\mathrm{LiOH}$ solution. For comparison, we have added the activity of commercial Pt/C catalyst from Tanaka. At $0.9 \mathrm{~V}$ vs. RHE the catalyst obtained by electrochemical route showed mass activity of $0.76 \mathrm{~A} / \mathrm{mg}$ which is $\sim 2$ times higher compared to commercial state of the art $\mathrm{Pt} / \mathrm{C}$ catalyst with $0.42 \mathrm{~A} / \mathrm{mg}$ mass activity. Moreover, the specific activity of the $\mathrm{Pt} / \mathrm{C}$ was $0.81 \mathrm{~mA} / \mathrm{cm}^{2}$ in comparison to that of commercial $\mathrm{Pt} / \mathrm{C}$, which is $0.61 \mathrm{~mA} / \mathrm{cm}^{2}$. This enhancement in the activity can be attributed to two factors: The first reason is the higher electrochemically active surface area per mass of the catalysts (so-called specific surface area, SSA). The SSA of commercial Pt/C catalyst is $68 \mathrm{~m}^{2} / \mathrm{g}$ and it is $94 \mathrm{~m}^{2} / \mathrm{g}$ for the $\mathrm{Pt} / \mathrm{C}$ catalysts prepared by the electrochemical approach. The higher SSA can be due to the specific surface structure on the individual nanoparticles as can be seen for instance in Fig. 4(a), and/or it can be due to better distribution of the Pt nanoparticles on the carbon support. Secondly, as it is seen from the PDF results the Pt nanoparticles prepared by electrochemical approach are strained, which in turn is beneficial in tailoring the binding energy of reaction intermediates of ORR. In addition, we investigated the stability of the Pt/C catalyst, the activities of fresh and after 1,000 cycles were comparable, as it can be seen in Fig. S4 in the ESM. Further electrocatalytic activity tests of different shapes and sizes towards various reactions are planned in future studies.

\section{Conclusions}

In this study, we systematically investigate the influence of the synthesis conditions on the geometry and structure of supported (and therefore isolated) Pt nanoparticles. In detail, this includes the influence of the applied potential amplitude, its frequency, the electrolyte concentration and the nature of the cations present in the electrolyte. Moreover, we derive

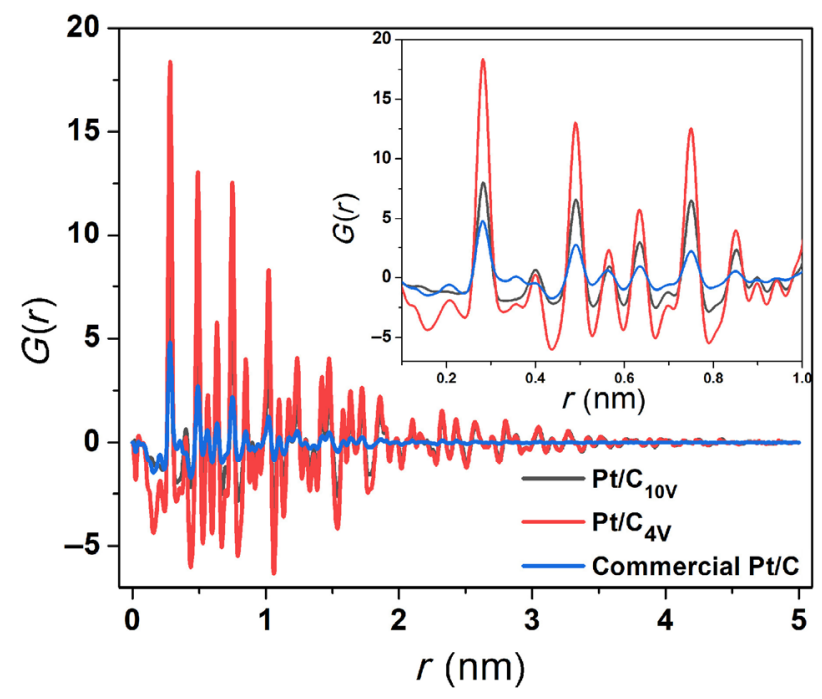

Figure 5 Experimental pair distribution functions for the $\mathrm{Pt} / \mathrm{C}_{10 \mathrm{~V}}, \mathrm{Pt} / \mathrm{C}_{4 \mathrm{~V}}$ and commercial Pt/C samples. Inset shows an enlarged section of the PDFs highlighting the nearest coordination environment. 

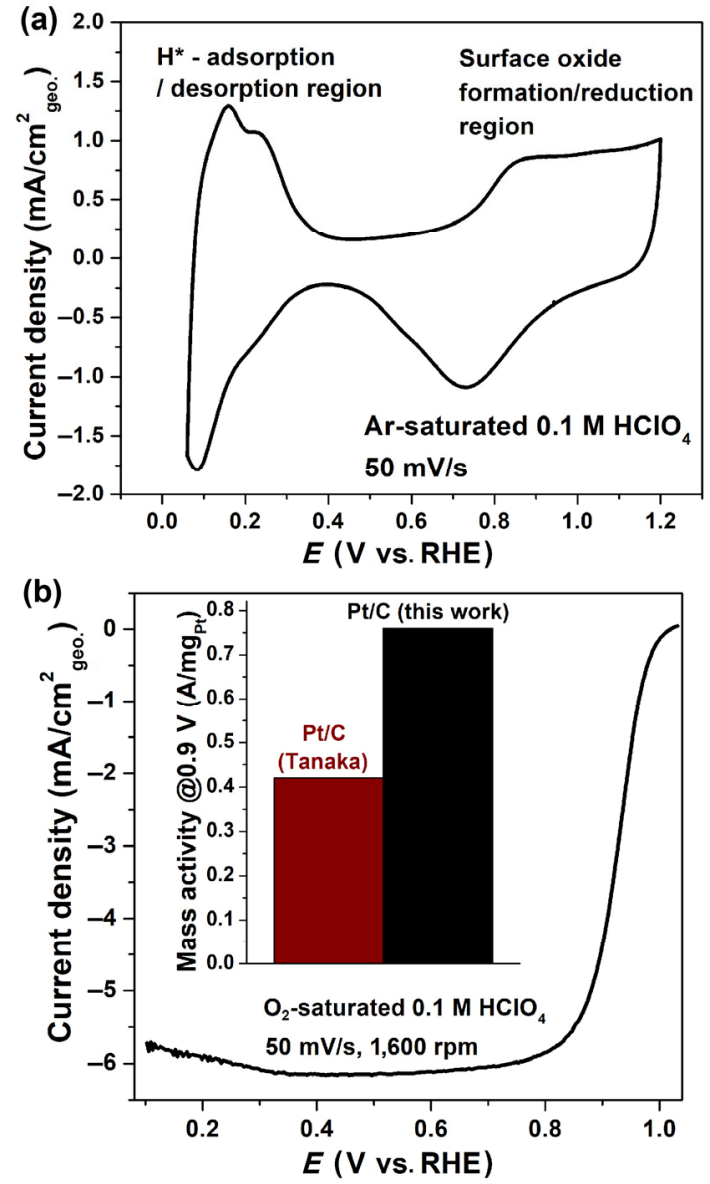

Figure 6 Activity of Pt/C towards oxygen reduction reaction. (a) Typical cyclic voltammogram of electrochemically prepared $\mathrm{Pt} / \mathrm{C}$ catalyst in Ar-saturated $0.1 \mathrm{M} \mathrm{HClO}_{4}$ at scan rate of $50 \mathrm{mV} / \mathrm{s}$. The hydrogen adsorption and desorption as well as the surface oxide formation and reduction peaks are labeled in the figure. (b) Typical $i R$-corrected polarization curve (anodic scan) of $\mathrm{Pt} / \mathrm{C}$ (electrochemically prepared) in $\mathrm{O}_{2}$-saturated $0.1 \mathrm{M} \mathrm{HClO}_{4}$ at the scan rate of $50 \mathrm{mV} / \mathrm{s}$ and the disk electrode was rotated at $1,600 \mathrm{rpm}$ Pt catalyst loading on the glassy carbon electrode was $20 \mu \mathrm{g}_{\mathrm{p}} / \mathrm{cm}^{2}$. The inset of the graph shows the mass activities at $0.9 \mathrm{~V}$ of commercial $\mathrm{Pt} / \mathrm{C}$ (Tanaka) and $\mathrm{Pt} / \mathrm{C}$ catalyst prepared in this work.

conclusions on the particle formation mechanism using the observations deduced from TEM images and PDF analysis of produced particles. Application of alternating voltage is important for fast generation of nanoparticles and higher frequencies generate spherical while lower frequencies generate cubical NPs. In addition, the alkali metal cations play a crucial role on the particle erosion from the bulk wire. The type of the alkali metal cations doesn't influence the structure of the generated species. However, lower electrolyte concentrations of alkali metal cations produce spherical while higher concentrations generate cubical structures. We also demonstrate the feasibility to synthesize nanoparticles in acidic electrolytes, granted alkali cations are present in the solution and the $\mathrm{pH}$ is higher than 2.5. PDF results show that this top-down approach forms strained nanostructures, indicating that the particles are likely to be carved out from the bulk rather than formed through metal ion dissolution. Furthermore, electrochemical activity results of $\mathrm{Pt} / \mathrm{C}$ catalyst prepared by this approach shows $\sim 2$-fold enhancement in the mass activity compared to the commercial $\mathrm{Pt} / \mathrm{C}$ catalyst from Tanaka. Hence, the electrochemical approach shows a promising way for a scalable top-down synthesis of metal NPs with desired geometry, and the mechanistic insights highlight which parameters can be tailored for optimal shape and size.

\section{Experimental}

Prior to the synthesis of carbon supported Pt nanoparticles (Pt/C), an electrolyte suspension was prepared. In detail, $\sim 20 \mathrm{mg}$ of "Vulcan" XC72R active carbon black (Cabot, USA) was dispersed in $\sim 25 \mathrm{~mL}$ of aqueous $\mathrm{MeOH}(\mathrm{Me}=\mathrm{Li}, \mathrm{Na}, \mathrm{K}$, Cs) solution via ultrasonication for $15 \mathrm{~min}$. Concentration of the alkali metal hydroxide solution was varied between 0.2 and $5 \mathrm{M}$. In order to improve hydrophilicity of the support material, "Vulcan" carbon black was pretreated in $30 \% \mathrm{H}_{2} \mathrm{O}_{2}$ solution (Rotipuran ${ }^{\circledR}$ p.a., Roth, Germany) for $24 \mathrm{~h}$, according to a procedure described elsewhere [30]. All experiments were conducted using ultrapure water (Evoqua, Germany).

Subsequently, two Pt wires ( $d=0.2 \mathrm{~mm}$; 99.99\%, Goodfellow, Germany), connected to a potentiostat, were immersed in the electrolyte and an AC voltage (sinusoidal or square wave) between specified potentials was applied to the wires. The frequency was varied between 20 and $400 \mathrm{~Hz}$. During the synthesis, the electrolyte was constantly stirred at $500 \mathrm{rpm}$. Following the application of the alternating potential, nanoparticles were produced and released into the electrolyte until the immersed fraction of wire was fully eroded. The deposited Pt weight fraction was controlled by measuring the weight of the $\mathrm{Pt}$ wires immersed into the electrolyte. To obtain the catalyst powder, the dispersion was stirred for $24 \mathrm{~h}$ at $500 \mathrm{rpm}$, washed with ultrapure water using a Büchner funnel and dried in a furnace at $60{ }^{\circ} \mathrm{C}$. In a typical synthesis, production rate of nanoparticles was ca. $\sim 0.5 \mathrm{mg} \mathrm{gt}_{\mathrm{p}} / \mathrm{min}$ for reported conditions (frequency $=200 \mathrm{~Hz}$, voltage amplitude $=10 \mathrm{~V}$, electrolyte $=1 \mathrm{M} \mathrm{KOH}, 1 \mathrm{~cm}$ of Pt wire immersed). However, it should be noted that the rate of particle formation depends on several parameters such as the electrolyte concentration, the amount of Pt wire that is immersed, applied frequency and applied potential amplitude.

For three-elecrode set-up procedure platinum wire $(0.25 \mathrm{~mm}$, 99.9 \%, Sigma Aldrich), a hydroflex electrode (Gaskatel $\mathrm{GmbH}$, Kassel, Germany) and graphite rod (Pine Instrument (Grove, City, PA, USA) were used as a working electrode (WE), reference electrode (RE) and counter electrode (CE), respectively. Synthesis was carried out in a $250 \mathrm{~mL}$ glassware with WE and CE, whereas a salt bridge was used to separate the RE. Carbon black (Vulcan XC72R, Fuel Cell Store, USA) was used as a support material and only in the two-electrode set-up to generate nanoparticles for TEM imaging. The three-electrode set-up was used to precisely control the WE potential. The mass of the Pt wire was measured before and after the experiment. The Pt wire was immersed into the solution with $3 \mathrm{~cm}$ exposed to the electrolyte. $\mathrm{N}_{2}$ was purged for $15 \mathrm{~min}$ before each experiment. A square wave potential was applied using a VSP potentiostat (Biologic Science Instruments). All experiments were carried out in ultrapure water $(18.2 \mathrm{M} \Omega / \mathrm{cm}, 3 \mathrm{ppb}$ TOC) generated by Milli-Q Integral water purification system. All glassware was washed by ultrapure water three times before each of the experiments. For the mechanistic studies ( $\mathrm{K}^{+}$effect), $200 \mathrm{~Hz}$ was applied for 3 or $5 \mathrm{~min}$ of varying square voltage amplitudes. During each experiment (without carbon black present) the solution was monitored for color changes, and the metal wire mass was measured to confirm formation of nanoparticles. Two experiments were conducted to explore the effect of $\mathrm{K}^{+}$ ions. In the first experiment the measurements were done in $70 \mathrm{~mL} 1 \mathrm{M} \mathrm{KOH}, 1 \mathrm{M} \mathrm{KOH}+0.5 \mathrm{M} \mathrm{KCl}$ and $1 \mathrm{M} \mathrm{KOH}+1 \mathrm{M}$ $\mathrm{KCl}$. The $\mathrm{KCl}$ powder was added to increase the concentration of $\mathrm{K}^{+}$ions without changing the volume and $\mathrm{pH}$ of electrolyte. In the second experiment $80 \mathrm{~mL}$ of $\mathrm{KCl}$ was titrated with $0 \mu \mathrm{L}$, $50 \mu \mathrm{L}, 400 \mu \mathrm{L}, 5 \mathrm{~mL}$ and $20 \mathrm{~mL}$ of $\mathrm{HCl}$, reaching $\mathrm{pH}$ of 5.35 , 
$3.22,2.5,1.42$ and 0.9 , respectively. The potential was set to $\pm 6 \mathrm{~V}$. An additional experiment was conducted in $80 \mathrm{~mL}$ of $\mathrm{HCl}$, with $\mathrm{pH}$ of $0.200 \mathrm{~Hz}$ frequency was used and experiment time was 3 min. Again, after each experiment the Pt wire was dried and weighted.

The morphology and particle size of the synthesized materials were investigated using TEM analysis. Typically, a few milligrams of sample were dispersed in 2-propanol/ultrapure water and then deposited onto a carbon-coated copper grid $(\mathrm{Cu}, 400$ mesh, formvar-carbon film, Science Services). The obtained samples were analyzed under a Philips CM100EM with an acceleration voltage of $100 \mathrm{kV}$ and a resolution of $0.5 \mathrm{~nm}$, and in Thermo Fisher Scientific TITAN Themis 60-300 Cubed with an acceleration voltage of $300 \mathrm{kV}$ and using STEM mode with BF and HAADF detectors for imaging with a resolution below $0.14 \mathrm{~nm}$.

Room temperature synchrotron total scattering experiments were performed at the Powder Diffraction and Total Scattering beamline (P02.1) at PETRA III, DESY, using $60 \mathrm{keV}(\lambda=$ $0.20708 \AA$ ) photon energy [31]. Diffraction patterns were collected using a PerkinElmer area detector at a sample-to-detector distance of $350 \mathrm{~mm}$. The exposure time for each diffraction pattern was $20 \mathrm{~min}$. Azimuthal data integration was carried out using the Fit2D program [32].

Powder samples were contained in sealed glass capillaries with $0.5 \mathrm{~mm}$ diameter. Data collection was performed under constant capillary spinning. Three samples, namely $\mathrm{Pt} / \mathrm{C}_{10 v}$, $\mathrm{Pt} / \mathrm{C}_{4 \mathrm{~V}}$ and commercial $\mathrm{Pt} / \mathrm{C}$ samples were measured along with "Vulcan" carbon and an empty capillary. Analysis of obtained diffraction patterns was performed by the full profile Rietveld method using the FullProf program package [33]. To model the peak profile shape, the pseudo-Voigt function was chosen. Background contribution was determined using a linear interpolation between selected data points in non-overlapping regions. The scale factor, profile shape, asymmetry and lattice parameter as well as isotropic displacement of $\mathrm{Pt}$ atoms (4a Wyckoff site, Fm-3m spacegroup) were varied during the fitting.

Corresponding PDF were calculated with $Q_{\max }=20 \AA^{-1}$ using GudrunX [34]. Simulations of the obtained PDFs was performed with PDFgui [35].

Powder X-ray diffraction data were obtained on a PANanalytical Empyrean instrument with a $\mathrm{Cu} \mathrm{K} \alpha$ radiation $(\lambda=1.5406 \AA)$ source and a slow scanning step $(1.5 \% \mathrm{~min})$ from $20^{\circ}$ to $90^{\circ}$. The voltage was $45 \mathrm{kV}$ and the intensity was $40 \mathrm{~mA}$, respectively.

The ORR performance of the $\mathrm{Pt} / \mathrm{C}$ (prepared in $1 \mathrm{M} \mathrm{LiOH}$, applying sinusoidal $\pm 10 \mathrm{~V}$, frequency $200 \mathrm{~Hz}$ ) was tested in rotating disk electrode configuration. Measurements were conducted in a $0.1 \mathrm{M} \mathrm{HClO}_{4}$ (Suprapur, Merck, Germany). As substrate for the catalyst film, a glassy carbon with a diameter of $5 \mathrm{~mm}$ and an area of $0.196 \mathrm{~cm}^{2}$ (Origalys, France) in combination with a OrigaTrod electrode rotator (Origalys, France) was used. A typical catalyst ink consisted of $\sim 10 \mathrm{mg}$ catalyst powder, $3.6 \mathrm{~mL}$ of ultrapure water, $1.466 \mathrm{~mL}$ of isopropanol (puriss, $>99.8 \%$, Sigma-Aldrich, Germany), and $0.03 \mathrm{~mL}$ of Nafion dispersion (5 wt.\% in lower aliphatic alcohols and water, Sigma-Aldrich, Germany). The exact same procedure was used for testing the performance of commercial $\mathrm{Pt} / \mathrm{C}$ catalyst (20 wt.\% Pt) from Tanaka (TEC10 V20E). An accelerated durability test (ADT) was performed to examine the long-term stability of the synthesized catalyst. The electrode was immersed in $0.1 \mathrm{M} \mathrm{HClO}_{4}$ and a square-wave potential was applied. The voltage was alternated between 0.60 and $1.00 \mathrm{~V}$, holding for $3 \mathrm{~s}$ at each potential. After 1000 accelerated durability test
(ADT) cycles the activity was evaluated using fresh electrolyte. The ADT measurements are shown in Fig. S4 in the ESM.

Pt loading was determined by thermogravimetric analysis (TGA) by using Mettler Toledo TG-MS equipment with heating speed of $50 \mathrm{~K} / \mathrm{min}$ to $1,100{ }^{\circ} \mathrm{C}$ and an air flow of $50 \mathrm{~mL} / \mathrm{min}$. Please see the TGA results in Fig. S5 in the ESM.

\section{Acknowledgements}

The financial support from Deutsche Forschungsgemeinschaft under Germany's excellence strategy - EXC 2089/1 - 390776260, Germany's excellence cluster "e-conversion", DFG project BA 5795/4-1, and funding from the TUM IGSSE project 11.01 are gratefully acknowledged. We also acknowledge DESY (Hamburg, Germany), a member of the Helmholtz Association HGF, for the provision of experimental facilities. Parts of this research were carried out at PETRA III using beamline P02.1. We acknowledge CzechNanoLab Research Infrastructure supported by MEYS CR (LM2018110) and CEITEC Nano Research Infrastructure for TEM measurements. We thank Mr. Shujin Hou for assisting with powder XRD measurements.

Funding note: Open Access funding enabled and organized by Projekt DEAL.

Electronic Supplementary Material: Supplementary material (X-ray diffraction data, accelerated durability testing, and thermogravimetrical analysis) is available in the online version of this article at https://doi.org/10.1007/s12274-020-3281-z.

Open Access This article is licensed under a Creative Commons Attribution 4.0 International License, which permits use, sharing, adaptation, distribution and reproduction in any medium or format, as long as you give appropriate credit to the original author(s) and the source, provide a link to the Creative Commons licence, and indicate if changes were made.

The images or other third party material in this article are included in the article's Creative Commons licence, unless indicated otherwise in a credit line to the material. If material is not included in the article's Creative Commons licence and your intended use is not permitted by statutory regulation or exceeds the permitted use, you will need to obtain permission directly from the copyright holder.

To view a copy of this licence, visit http://creativecommons.org/licenses/by/4.0/.

\section{References}

[1] Chen, A. C.; Holt-Hindle, P. Platinum-based nanostructured materials: Synthesis, properties, and applications. Chem. Rev. 2010, 110, 3767-3804.

[2] Pedone, D.; Moglianetti, M.; De Luca, E.; Bardi, G.; Pompa, P. P. Platinum nanoparticles in nanobiomedicine. Chem. Soc. Rev. 2017, 46, 4951-4975.

[3] Langer, J.; de Aberasturi, D. J.; Aizpurua, J.; Alvarez-Puebla, R. A.; Auguié, B.; Baumberg, J. J.; Bazan, G. C.; Bell, S. E. J.; Boisen, A.; Brolo, A. G. et al. Present and future of surface-enhanced Raman scattering. ACS Nano 2020, 14, 28-117.

[4] Fichtner, J.; Watzele, S.; Garlyyev, B; Kluge, R. M.; Haimerl, F.; El-Sayed, H. A.; Li, W. J.; Maillard, F. M.; Dubau, L.; Chattot, R. et al. Tailoring the oxygen reduction activity of Pt nanoparticles through surface defects: A simple top-down approach. ACS Catal. 2020, 10, 3131-3142.

[5] Fichtner, J.; Garlyyev, B.; Watzele, S.; El-Sayed, H. A.; Schwämmlein, J. N.; Li, W. J.; Maillard, F.; Dubau, L.; Michalička, J.; Macak, J. M. et al. Top-down synthesis of nanostructured platinum-lanthanide alloy oxygen reduction reaction catalysts: $\mathrm{Pt} x \mathrm{Pr} / \mathrm{C}$ as an example. $A C S$ Appl. Mater. Interfaces 2019, 11, 5129-5135. 
[6] Rück, M.; Garlyyev, B.; Mayr, F.; Bandarenka, A. S.; Gagliardi, A. Oxygen reduction activities of strained platinum core-shell electrocatalysts predicted by machine learning. J. Phys. Chem. Lett. 2020, 11, 1773-1780.

[7] Mahmoud, M. A.; Garlyyev, B.; El-Sayed, M. A. Controlling the catalytic efficiency on the surface of hollow gold nanoparticles by introducing an inner thin layer of platinum or palladium. J. Phys. Chem. Lett. 2014, 5, 4088-4094.

[8] Strasser, P.; Gliech, M.; Kuehl, S.; Moeller, T. Electrochemical processes on solid shaped nanoparticles with defined facets. Chem. Soc. Rev. 2018, 47, 715-735.

[9] Garlyyev, B.; Liang, Y. C.; Butt, F. K.; Bandarenka, A. S. Engineering of highly active silver nanoparticles for oxygen electroreduction via simultaneous control over their shape and size. Adv. Sustainable Syst. 2017, $1,1700117$.

[10] Xia, Y. N.; Gilroy, K. D.; Peng, H. C.; Xia, X. H. Seed-mediated growth of colloidal metal nanocrystals. Angew. Chem., Int. Ed. 2017, $56,60-95$.

[11] Mahmoud, M. A.; Garlyyev, B.; El-Sayed, M. A. Wavelength-selective photocatalysis using gold-platinum nanorattles. J. Phys. Chem. C 2015, 119, 18618-18626.

[12] Xia, W.; Mahmood, A.; Zou, R. Q.; Xu, Q. Metal-organic frameworks and their derived nanostructures for electrochemical energy storage and conversion. Energy Environ. Sci. 2015, 8, 1837-1866.

[13] Garlyyev, B.; Kratzl, K.; Rück, M.; Michalička, J.; Fichtner, J.; Macak, J. M.; Kratky, T.; Günther, S.; Cokoja, M.; Bandarenka, A. S. et al. Optimizing the size of platinum nanoparticles for enhanced mass activity in the electrochemical oxygen reduction reaction. Angew. Chem., Int. Ed. 2019, 58, 9596-9600.

[14] Haber, F. The phenomenon of the formation of metallic dust from cathodes. Trans. Am. Electrochem. Soc. 1902, 2, 189-196.

[15] Yanson, A. I.; Rodriguez, P.; Garcia-Araez, N.; Mom, R. V.; Tichelaar, F. D.; Koper, M. T. M. Cathodic corrosion: A quick, clean, and versatile method for the synthesis of metallic nanoparticles. Angew. Chem., Int. Ed. 2011, 50, 6346-6350.

[16] Hersbach, T. J. P.; McCrum, I. T.; Anastasiadou, D.; Wever, R.; Calle-Vallejo, F.; Koper, M. T. M. Alkali metal cation effects in structuring Pt, Rh, and Au surfaces through cathodic corrosion. ACS Appl. Mater. Interfaces 2018, 10, 39363-39379.

[17] Leontyev, I.; Kuriganova, A.; Kudryavtsev, Y.; Dkhil, B.; Smirnova, N. New life of a forgotten method: Electrochemical route toward highly efficient $\mathrm{Pt} / \mathrm{C}$ catalysts for low-temperature fuel cells. Appl. Catal. A 2012, 431-432, 120-125.

[18] Duca, M.; Rodriguez, P.; Yanson, A. I.; Koper, M. T. M. Selective electrocatalysis on platinum nanoparticles with preferential (100) orientation prepared by cathodic corrosion. Top. Catal. 2014, 57, 255-264.

[19] Rodriguez, P.; Plana, D.; Fermin, D. J.; Koper, M. T. M. New insights into the catalytic activity of gold nanoparticles for $\mathrm{CO}$ oxidation in electrochemical media. J. Catal. 2014, 311, 182-189.

[20] Kromer, M. L.; Monzó, J.; Lawrence, M. J.; Kolodziej, A.; Gossage, Z. T.; Simpson, B. H.; Morandi, S.; Yanson, A.; Rodríguez-López, J.; Rodríguez, P. High-throughput preparation of metal oxide nanocrystals by cathodic corrosion and their use as active photocatalysts.
Langmuir 2017, 33, 13296-13302.

[21] Lawrence, M. J.; Kolodziej, A.; Rodriguez, P. Controllable synthesis of nanostructured metal oxide and oxyhydroxide materials via electrochemical methods. Curr. Opin. Electrochem. 2018, 10, 7-15.

[22] Lawrence, M. J.; Celorrio, V.; Shi, X. B.; Wang, Q.; Yanson, A.; Adkins, N. J. E.; Gu, M.; Rodríguez-López, J.; Rodriguez, P. Electrochemical synthesis of nanostructured metal-doped titanates and investigation of their activity as oxygen evolution photoanodes. ACS Appl. Energy Mater. 2018, 1, 5233-5244.

[23] Rodriguez, P.; Tichelaar, F. D.; Koper, M. T. M.; Yanson, A. I. Cathodic corrosion as a facile and effective method to prepare clean metal alloy nanoparticles. J. Am. Chem. Soc. 2011, 133, 17626-17629.

[24] Monzó, J.; van der Vliet, D. F.; Yanson, A.; Rodriguez, P. Elucidating the degradation mechanism of the cathode catalyst of PEFCs by a combination of electrochemical methods and X-ray fluorescence spectroscopy. Phys. Chem. Chem. Phys. 2016, 18, 22407-22415.

[25] Yanson, A. I.; Antonov, P. V.; Rodriguez, P.; Koper, M. T. M. Influence of the electrolyte concentration on the size and shape of platinum nanoparticles synthesized by cathodic corrosion. Electrochim. Acta 2013, 112, 913-918.

[26] Hersbach, T. J. P.; Yanson, A. I.; Koper, M. T. M. Anisotropic etching of platinum electrodes at the onset of cathodic corrosion. Nat. Commun. 2016, 7, 12653.

[27] Garlyyev, B.; Fichtner, J.; Piqué, O.; Schneider, O.; Bandarenka, A. S.; Calle-Vallejo, F. Revealing the nature of active sites in electrocatalysis. Chem. Sci. 2019, 10, 8060-8075.

[28] Calle-Vallejo, F.; Pohl, M. D.; Reinisch, D.; Loffreda, D.; Sautet, P.; Bandarenka, A. S. Why conclusions from platinum model surfaces do not necessarily lead to enhanced nanoparticle catalysts for the oxygen reduction reaction. Chem. Sci. 2017, 8, 2283-2289.

[29] Seitsonen, A. P.; Zhu, Y. J.; Bedürftig, K.; Over, H. Bonding mechanism and atomic geometry of an ordered hydroxyl overlayer on Pt(111). J. Am. Chem. Soc. 2001, 123, 7347-7351.

[30] Carmo, M.; Linardi, M.; Poco, J. G. R. $\mathrm{H}_{2} \mathrm{O}_{2}$ treated carbon black as electrocatalyst support for polymer electrolyte membrane fuel cell applications. Int. J. Hydrog. Energy 2008, 33, 6289-6297.

[31] Dippel, A. C.; Liermann, H. P.; Delitz, J. T.; Walter, P.; SchulteSchrepping, H.; Seeck, O. H.; Franz, H. Beamline P02.1 at PETRA III for high-resolution and high-energy powder diffraction. $J$. Synchrotron Rad. 2015, 22, 675-687.

[32] Hammersley, A. P.; Svensson, S. O.; Hanfland, M.; Fitch, A. N.; Hausermann, D. Two-dimensional detector software: From real detector to idealised image or two-theta scan. High Pressure Res. 1996, 14, 235-248.

[33] Rodríguez-Carvajal, J. Recent developments of the program FULLPROF, in commission on powder diffraction (IUCr). Newsletter 2001, 26, 12-19.

[34] Soper, A. K.; Barney, E. R. Extracting the pair distribution function from white-beam X-ray total scattering data. J. Appl. Cryst. 2011, 44, 714-726.

[35] Farrow, C. L.; Juhas, P.; Liu, J. W.; Bryndin, D.; Božin, E. S.; Bloch, J.; Proffen, T.; Billinge, S. J. L. PDFfit2 and PDFgui: Computer programs for studying nanostructure in crystals. J. Phys.: Condens. Matter 2007, 19, 335219. 